\title{
Availability of safe drinking-water: the answer to cholera outbreak? Nabua, Camarines Sur, Philippines, 2012
}

\author{
Alethea De Guzman, ab Vikki Carr de los Reyes, ${ }^{b}$ Ma Nemia Sucalditob and Enrique Tayag ${ }^{b}$ \\ Correspondence to Alethea De Guzman (email: aletheardeguzman@gmail.com).
}

Background: In May 2012, there were increasing diarrhoea cases and deaths reported from Nabua, Camarines Sur to the Philippines event-based surveillance system. An investigation was conducted to identify risk factors and determine transmission dynamics.

Methods: A suspected case was defined as a resident of Nabua with at least three episodes of watery diarrhoea per day from 16 March to 22 June 2012. A confirmed case was defined as a suspected case positive for Vibrio cholerae. An environmental investigation was conducted and rectal swabs and water samples sent to the national reference laboratory for bacterial isolation. A 1:2 case-control study matching for age and sex was conducted. Data were analyzed using Epi Info.

Results: There were 309 suspected cases with two deaths, and the most affected age group was children under five years (45\%). Eight cases were positive for Vibrio cholerae Ogawa El Tor and one for Non-01. Water samples were positive for faecal coliforms and Aeromonas caviae. The case-control study showed that cases had a higher odds than controls of using unchlorinated water sources (odds ratio $[\mathrm{OR}]=3.6$; 95\% confidence interval $[\mathrm{Cl}]: 1.6-8.5$ ) and having toilets located within 20 metres of a septic tank (OR $=2.7 ; 95 \% \mathrm{Cl}: 1.4-5.3)$. In multivariate analysis, the only significant factor was drinking from piped water (OR $=0.21 ; 95 \% \mathrm{Cl}: 0.09-0.49)$.

Discussion: In this cholera outbreak, drinking-water from unchlorinated wells was a significant risk factor. Future cholera control efforts should include not just improving water and sanitation systems but also intensified behaviour change campaigns.

$\mathrm{C}$ holera is an acute gastrointestinal infection caused by ingestion of food or water contaminated with Vibrio cholera and presents with severe watery diarrhoea which can lead to dehydration and death if not immediately treated. ${ }^{1}$ Ensuring access to adequate supplies of safe water has traditionally been the primary response to cholera.

Nabua is located in Camarines Sur, a province in the Bicol Region of the Philippines. It has 42 villages, a population of $82614^{2}$ and two main health centres. Local surveillance data had no recorded cholera outbreaks for the period 2008-2012. ${ }^{3}$

In May 2012, there were increasing numbers of diarrhoea cases and deaths reported from Nabua on the event-based surveillance system. A team from the Philippines Field Epidemiology Training Program and local health offices were sent to identify risk factors and better understand the transmission in the outbreak.

\section{METHODS}

\section{Descriptive study}

A descriptive study was conducted by reviewing medical records from the main health centres and the two referral hospitals near Nabua. A suspected cholera case was defined as a previously well resident of Nabua, Camarines Sur who had at least three episodes of watery diarrhoea per day from 16 March to 22 June 2012. A confirmed case was a suspected case positive for Vibrio cholerae by bacterial stool culture.

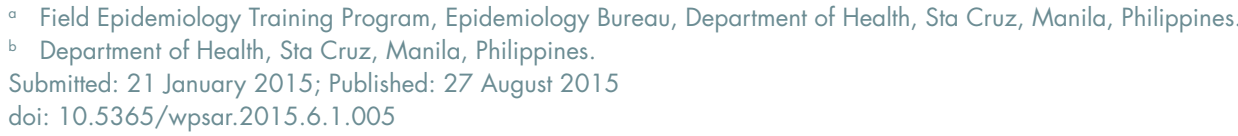


Figure 1. Cholera cases by date of onset of illness, Nabua, Camarines Sur, Philippines, 10 March to 28 June 2012 $(n=309)$

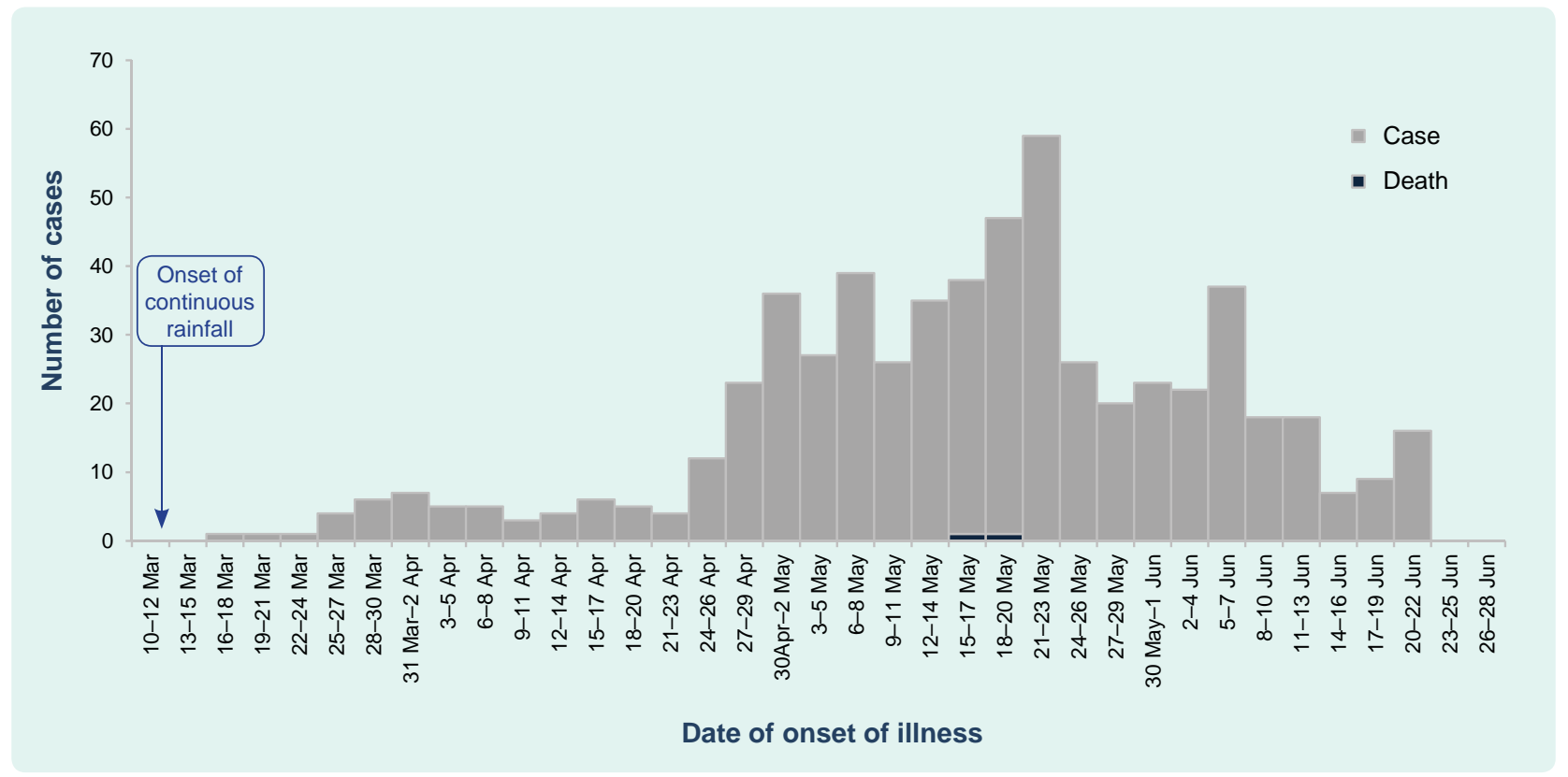

\section{Case-control study}

We conducted a 1:2 case-control study, matching for age and sex, in villages with the highest attack rates. A subset of all suspected cases was included due to time constraints. A control was defined as a well resident of Nabua who was negative for Vibrio cholerae on laboratory examination. We selected cases through purposive sampling from the line list. For each case selected, we identified two controls from within the same household and/or household nearest to the case. We interviewed cases and controls using a standard questionnaire which included information on water sources, hygiene and sanitation practices and other environmental factors. We validated cause of death by verbal autopsy. ${ }^{4}$ Data were entered and bivariate and multivariate analyses done using Epi Info version 3.5.4.

All cases and controls signed a consent form for the interview and sample collection.

\section{Laboratory testing}

Rectal swabs were collected at the beginning of the investigation and active case finding. The interval between sample collection and onset of symptoms ranged from a few days to one month. Rectal swabs were placed in Cary-Blair transport media, stored at room temperature and sent to the laboratory within two days of collection.
Water samples were collected through aseptic technique and placed in a one-litre sterilized bottle. Samples were tested for bacterial isolation and susceptibility by the national reference laboratory.

\section{Environmental investigation}

We interviewed health centre staff regarding surveillance data, cholera case diagnosis and management and water and sanitation status; we assessed these through an environmental survey. We also interviewed the manager of the Level III water system to identify which villages had access to the system and how water quality was monitored.

Water sources from the most affected villages and the Level III water system were assessed. We inspected for leaks, possible entries for contamination and the sanitary conditions of the area surrounding the water sources.

\section{RESULTS}

\section{Descriptive study}

There were 309 suspected cases identified. The onset date of the first case was 16 March, with a peak of cases on 21 May (Figure 1). Of the cases, $37(12 \%)$ were hospitalized and two died (case fatality rate $=0.6 \%$ ). 
Table 1. Water and environmental factors associated with cholera, Nabua, Camarines Sur, Philippines, 10 March to 28 June 2012

\begin{tabular}{lcccc}
\hline \multicolumn{1}{c}{ Factors } & Case $(\boldsymbol{n}=\mathbf{5 5})$ & Control $(\boldsymbol{n}=\mathbf{1 1 0})$ & Odds ratio & $P$-value \\
\hline Drinking from free-flow wells & $20(37 \%)$ & $16(15 \%)$ & 3.62 & 0.001 \\
Drinking from open dug wells & $25(45 \%)$ & $43(39 \%)$ & 2.81 & 0.028 \\
Toilets located within 20 m of water sources & $38(69 \%)$ & $50(45 \%)$ & 2.68 & 0.002 \\
Drinking from piped water system & $8(14 \%)$ & $48(44 \%)$ & 0.22 & $<0.001$ \\
Female (sex) & $32(58 \%)$ & $63(57 \%)$ & 1.04 & 0.960 \\
Boiling water & $16(29 \%)$ & $35(32 \%)$ & 0.88 & 0.860 \\
Owning a toilet & $41(74 \%)$ & $94(86 \%)$ & 0.50 & 0.140 \\
Using ice in drinking-water & $40(77 \%)$ & $78(71 \%)$ & 1.09 & 0.950 \\
Washing hands after using toilet & $54(98 \%)$ & $110(100 \%)$ & 0.00 & 0.720 \\
\hline
\end{tabular}

Both deaths presented with severe diarrhoea; one was an elderly male. Neither case sought consultation at a health facility. Aside from acute watery diarrhoea, other signs and symptoms of cases included abdominal pain (26\%), mild dehydration (22\%) and vomiting (21\%). Only the two $(0.6 \%)$ deaths presented with severe dehydration.

There were 158 (51\%) male cases ranging from 3 months to 92 years (median $=1$ year); there were 140 cases (45\%) aged less than 5 years. There were 28 villages affected; the highest attack rate was 3.9\%.

\section{Case-control study}

There were 55 cases and 110 controls interviewed. In bivariate analysis, cases had three times the odds of having drunk from free-flow wells (odds ratio $[O R]=3.6$; 95\% confidence interval [Cl]: 1.6-8.5) and open dug wells $(\mathrm{OR}=2.8 ; 95 \% \mathrm{Cl}: 0.97-8.2)$ and were approximately three times more likely to use a toilet within 20 metres of a water source $(\mathrm{OR}=2.7 ; 95 \% \mathrm{Cl}: 1.35-5.32)$ than controls (Table 1). Cases had 0.22 times the odds of drinking from the piped water system compared with controls. In multivariate analysis, the only significant factor was drinking from the piped water system, which was inversely related with being a case $(O R=0.21$; 95\% Cl: 0.09-0.49).

Common reasons given for not using boiled or chlorinated water were that residents did not like the taste or smell of boiled or chlorinated water and that boiling and chlorination took too much time and was costly.

\section{Laboratory testing}

Of the 222 rectal swabs collected, eight (4\%) were positive for Vibrio cholerae Ogawa El Tor and one $(0.5 \%)$ for Vibrio cholerae Non-01. However, 102 cases were given antibiotics before sample collection. Culture tests were negative for all other bacteria. All controls were negative for Vibrio cholerae and other bacterial culture tests.

Four water samples were positive for coliform bacteria; two (20\%) of 10 water samples were positive for Aeromonas caviae; no samples were positive for Vibrio cholerae.

\section{Environmental investigation}

The local government-owned Nabua Water District (NWD) managed a piped water system supplying chlorinated water to 36 (86\%) villages. The NWD's records showed that water samples were submitted monthly to the regional health office for bacteriologic testing and were negative for faecal contamination. Annual physico-chemical testing of water collected at the intake passed national standards. ${ }^{5}$

Villages not supplied by the NWD used unchlorinated free-flow or open dug wells for drinking and domestic water sources. All 165 residents interviewed had access to the NWD water system, but only $38(23 \%)$ used it as a water source. Two major reasons identified were that residents reported no perceived benefit of a chlorinated water source since no cases of cholera had been previously reported, and the installation of a Level III 
chlorinated system entails additional cost to residents. There was no local quality monitoring committee, and the last water analysis of these wells was conducted more than five years ago.

Health centre staff revealed that villages along the Bicol River were usually flooded during heavy rainfall that began several weeks before the outbreak. The five villages with the highest attack rates were located in these flooded areas. We observed that wells were located within 20 metres of a septic tank and open defecation sites. Two (20\%) of 10 wells inspected had visibly leaking pipes.

\section{Control and prevention measures}

After the investigation, local health officials conducted household health education with emphasis on household chlorination or boiling. They inspected all water sources, closed contaminated wells and regularly chlorinated other water sources. Officials also expanded the Level III water system to other villages and established a Local Water Quality Monitoring Committee to ensure the community's access to safe water.

\section{DISCUSSION}

In this cholera outbreak, we identified drinking from unchlorinated wells as a significant risk factor; drinking from the piped water system was inversely associated with illness. Environmental testing of well water showed evidence of faecal contamination. The outbreak stopped when these water sources were chlorinated and households began to boil or chlorinate their drinkingwater.

Cholera infection results from water and food contamination. The proximity of water sources to toilets and waste were possible reasons for contamination in this outbreak as heavy rain flooded these wells. As rivers are nutrient-rich environments, changes in their bacterial flora can lead to increases in plankton blooms associated with cholera outbreaks. ${ }^{6}$ Floodwaters may have also mixed with run-off from surrounding septic tanks. Contamination of the water table was likely since the wells were improperly maintained and not monitored. This could explain the spread of contamination to wells unaffected by flooding.
That $77 \%$ of villagers who had access to chlorinated water chose to drink from untreated wells also contributed to this outbreak. Despite the increase in diarrhoea cases and deaths, households still did not treat their drinking-water. It was only after the investigators recommended enhanced health education activities emphasizing the importance of treating drinking-water sources that households complied. Lastly, the practice of open defecation was a possible source of well water contamination.

We isolated 01 Ogawa El Tor and Non-O1 in this outbreak. These two types usually present with less severe disease versus the classical type. ${ }^{7}$ This was consistent with our findings of milder signs and symptoms and a low case fatality rate.

One limitation of the study was that by the time of the investigation, cases were already treated with antibiotics and water sources had been initially chlorinated. This could explain the low positivity rate in both clinical and environmental specimens. There may be recall bias among study participants since the investigation was conducted almost two months after the outbreak began.

The standard recommendation in a cholera outbreak is to make available safe, chlorinated water. In this outbreak, availability of chlorinated water did not stop transmission. Behavioural factors played a major role in sustaining transmission. Future cholera control efforts should include public health programmes focused on behaviour change.

\section{Conflicts of interests}

None declared.

Funding

None.

\section{Acknowledgements}

We are grateful for the cooperation and support of the Center for Health and Development-Bicol, the Research Institute for Tropical Medicine, Camarines Sur Provincial Health Office, the local government of Nabua and town residents during the field investigation. 


\section{References}

1. Heymann D. Control of Communicable Diseases Manual 19th Edition. Washington, DC, American Public Health Association, 2008.

2. Field Health Services Information System Annual Report: 2012. Camarines Sur, Nabua Municipal Health Office, 2012.

3. Philippine Integrated Disease Surveillance and Response Annual Report: 2008-2012. Albay, Department of Health Region V, 2012.

4. Verbal autopsy standards: the 2012 WHO verbal autopsy instrument. Geneva, World Health Organization, 2012 (http://
www.who.int/healthinfo/statistics/WHO VA 2012 RC1 Instrument.pdf, accessed 30 July 2015).

5. Administrative Order No. 2007-0012: Philippine national standards for drinking-water, 9 March 2007. Manila, Department of Health, 2007.

6. Jutla AS et al. Warming oceans, phytoplankton, and river discharge: implications for cholera outbreaks. The American Journal of Tropical Medicine and Hygiene, 2011, 85:303-308. doi:10.4269/ajtmh.2011.11-0181 pmid:21813852

7. Ghosh-Banerjee J et al. Cholera toxin production by the EI Tor variant of Vibrio cholerae 01 compared to prototype El Tor and classical biotypes. Journal of Clinical Microbiology, 2010, 48:42834286. doi:10.1128/JCM.00799-10 pmid:20810767 